\title{
Making Cast Ammunition in France
}

\section{How Semi-Steel Shells Are Made-Composition and the Physical Properties \\ By E. Ronceray}

THE war which has been engaging the attention of the civilized world for nearly four years has made necessary the introduction of new processes in the foundry as well as in other industries. The need tor ammunition is great and exceeds what was conceived to be necessary, even by the most visionary. It is a well-known fact that five weeks after the declaration of war, the battle of the Marne ended when the French and Germans had practically exhausted their entire supply of shells. It was a tragic and critical moment and every means was resorted to to obtain shells, even though imperfect.

It was at this time that practice shells, made of cast iron and containing only a small amount of explosive were used and these were produced as quickly as the foundries could turn them out. The 75-millimeter (2.96 in.) steel shell gave such excellent results that every effort was made to secure them and even small shop were asked to bore and thread steel bars to produce these shells in two parts, one for the body and one for the cap. This imperfect type of shell and that made of cast iron saved the day for the $75-\mathrm{mm}$. rapid fire gun which was the most important weapon in use at that time. Steps were taken immediately for the manufacture of forged shells on an extensive scale and the output at present is so great that we are furnishing large quantities of them to our Allies.

A different problem was presented in providing shells for the large guns. With the increase in the diameter of the shells, manufacturing difficulties increased more rapidly. More time was required to make the large shells and to organize for their producision in larg quantities. It was then that the feasibility of using cast shells was seriously considered.

It is well known among ordnance experts that the destructive effect of a projectile increases in proportion to its size more rapidly than the weight of the explosive it contains. Therefore, steel had the preference for shell in spite of the great cost of the raw material and the high cost of machining. Cast iron shells used as substitutes for steel were of a small capacity on account of the great thickness of wall it was necessary to provide, to insure adequate resistance to the ballistic action of the powder.

SEMI-STEEL SHELLS

The fonte acieree, that is, cast material and what is known as semi-steel, was considered and was selected finally for producing a comparatively cheap, quickly manufactured and reasonably effective shell. The Germans can vouch for this. Since the beginning of 1915 , an enormous number of these projectiles from 80 1915 , an enormous number of these projectiles from 80
to $400 \mathrm{~mm}$. ( 3.15 to $15.71 \mathrm{in}$.) have been made and fired to $400 \mathrm{~mm}$. ( 3.15 to $15.71 \mathrm{in}$.) have been made and fired
for the cause of civilization. In addition to the semifor the cause of civilization. In addition to the semi-
steel shells, an enormous amount of grenades and projectiles of all kinds have been made of cast iron in France.

The metal required for semi-steel shells was defined by the following data, based on the tests made in thi country by the ordnance authorities and railroad companies. The test piece is a square bar, $40 \times 40 \times 200 \mathrm{~mm}$ panies. The test piece is a square bar, $40 \times 40 \times 200 \mathrm{~mm}$
$(1.57 \times 1.57 \times 7.85$ in.) long, cast on end in green sand with a riser. It is tested on two knives spaced $160 \mathrm{~mm}$ (6.30 in.) apart, by a falling weight of $12 \mathrm{~kg}$. (26.41 lb.) The initial drop is from a height of $28 \mathrm{~cm}$. (11 in.) and the weight is raised $1 \mathrm{~cm}$. (0.254 in.) after each blow until rupture occurs. The average breaking height must not be less than $45 \mathrm{~cm}$. (17.71 in.)

The tensile test piece is $18 \mathrm{~mm}$. (0.71-in.) in diamete x $150 \mathrm{~mm}$. (5.91 in.) long, cast on end and turned down to $16 \mathrm{~mm}$. (0.63 in.). The breaking strain must not b less than $25 \mathrm{~kg}$. per sq. mm. (39,900 lb. per sq. in.)

Hydraulic tests of 10 sec. duration, before banding, are made at a pressure of $300 \mathrm{~kg}$. per sq. cm. $(4,500 \mathrm{lb}$ per sq. in.) for the shells up to $160 \mathrm{~mm}$. (6.30 in.) and 200 kg. (3,000 lb. per sq. in.) for the larger sizes. Other test after banding are made with compressed air or steam at $5 \mathrm{~kg}$. per sq. mm. (75 lb. per sq. in.)

A reasonable allowance is made for small defects difficult to eliminate entirely in practice, particularly when great production is required. Small defects externally in front of the band are passed provided their thicknes can be determined exactly with a needle and extend into the metal less than one-fourth of the wall thickness.

No defects are permitted at the back of the band except small, interior depressions due to impertect coring, provided that the thickness is not more than 2 or $3 \mathrm{~mm}$. $(0.079$ to 0.118 -in.) and that the bottom of the shell is sound.

*From a paper prepared for the American Foundrymen's Association. The author is a member of the association and lives
at 9 Rue des Envierges, Paris, France.-Reported in the Iron Age.

\section{COMPOSITION OF THE METAL}

No definite analysis is enforced provided the physical tests are satisfactory. In fact, the metal is a low phosphorus, low sulphur and low carbon iron with a suffciently high amount of silicon and a sufficiently low amount of manganese to leave it soft under the conditions of pouring. Typical analyses of semi-steel shells follow:

\begin{tabular}{|c|c|c|}
\hline & $\begin{array}{l}\text { Diameter of Shell } \\
150 \mathrm{~mm} .(4.74 \text { in.), } \\
\text { Per Cent. }\end{array}$ & $\begin{array}{c}\text { Diameter of Shell } \\
155 \mathrm{~mm} . ; 6.11 \text { in.) } \\
\text { Per Cent. }\end{array}$ \\
\hline Total carbon. & 3.25 & 3.06 \\
\hline Silicon. . & 1.34 & 1.17 \\
\hline Manganese. . & 0.66 & 0.61 \\
\hline Phosphorous......... & 0.08 & 0.08 \\
\hline Sulphur... & 0.10 & 0.17 \\
\hline
\end{tabular}

To obtain a very strong metal it may be melted either in an open-hearth or electric furnace, which insures a low carbon product with some degree of certainty, or by mixing cupola and converter metal. Thermic treatment will considerably improve the physical qualities. Tensile strengths of 35 to $40 \mathrm{~kg}$. per sq. mm. $\quad(50,000$ to obtained regularly by these processes. This metal, however, increases the casting difficulties as it has a tendency to develop blowholes owing to its lack of fluidity. However, for the heavy tonnages required in a short time, the cupola, well handled, gives satistactory results and regularly produces metal that passes the necessary physical tests. The bulk of the semi-steel shells made in France, either for the Allies, or for ourselves, have been cast of cupola metal.

$$
\text { THE CUPOLA AND ITS EQUITMENT }
$$

The standard cupola, as built in America, is capable of producing good semi-steel. The tuyeres, usually one or two rows close to each other in large cupolas, must be of the standard type, that is, flat and one-sixth to oneto employ a cupola, equipped either with a hearth for holding a certain amount of metal, or provided with a holding a certain amount of metal, or provided with a
receiver. The use of a receiving ladle is not recomreceiver. The use of a receiving ladle is not recom-
mended, as very hot metal with regularity of composition is essential. If a cupola equipped with a receiver is employed, provision must be made to heat the receiver while hot before pouring, or the first metal will be dull.

A blower of ample size is required and it is more advisable to have one of too large a capacity than one that must be driven to the limit to provide sufficient blast. I prefer a positive pressure blower to a fan, as the former insures better control of the melting.

$$
\text { SAND LINING FOR THE CUPOLA }
$$

The best lining is none too good as all operating conditions are against its long life. The extended heats necessitated by the large outpu's required, the exceedingly hot temperature needed for good metal, the large amount of coke burnt at each melt combined with its low quality at the present time and the large amount of limestone generally used, result in the rapid wear of the lining. Owing to the high cost and scarcity of refractory material in France, many foundrymen have adopted sand linings and it must be admitted that in a great many instances these linings have given equal, if not better results, than refractory brick. A good refractory sand is selected for this purpose and it should be rammed hard between the shell of the cupola and a wood form. It is then carefully dried and blacked. In wearing qualities it compares favorably with the best refractory brick. A thick lining, 12 inches or more, is recommended.

The proportion of steel used in the mixture depends on the composition of the initial iron. If low carbon irons are employed, the amount of steel added must be less than it high carbon pig is used in the mixture. As a rule, the hematite irons now supplied contain more carbon than required, cold blast iron with low carbon content not being produced here in large quantities. Therefore, it is necessary to add a large amount of steel to the charges in order to reduce carbon in the final product. It is admitted that in the cupola process, steel before melting, absorbs 1.6 to 2 per cent of carbon. Taking this into account it is easy to calculate hov much steel must be added to reduce the carbon percentage to the correct point. In French practice, up to 40 and even 50 per cent of steel is used. The amount generally charged, however, is from 15 to 30 per cent, according to the quality of the initial iron.

COMPOSITION OF THE FINAL PRODUCT

The final product varies for different sizes of shells and according to the methods of molding pursued. The shell casting must be softer for the smaller projectile, or more exactly, for the thinner shell, and also it must be softer when the metal is poured in green sand molds than in dry sand. The physical properties of the test bars do not measure the final quality of the product. Theretore, test bars from the projectiles themselves are necessary. Such tests, together with actual firing practice, have shown that the best results are obtained when at least 20 per cent of the total carbon is in the combined form, this percentage being as high as consistent with the possibility of machining the shells. The total carbon is kept at about 3 per cent. Less than 2.75 per cent gives a sluggish metal which is difficult to handle and liable to produce unsound castings. Above 3.25 per cent carbon results in the production of castings that are too weak.

Several methods are pursued for controlling the combined carbon. One is to alter the amount of silicon another is to change the amount of manganese which seems to act in opposition to the silicon, and a third is to change the speed of cooling. Silicon precipitates carbon in the graphitic form and, consequently, reduces combined carbon; manganese has a reverse action, while combined carbon increases with the speed of cooling.

Since the amount of manganese in the iron and stee we are using is about right, it has not been the practice to vary their percentages according to the silicon content. The speed of cooling is not easy to control and the only Thensideration given this factor is in connection with the change that takes place when the thickness of the shell is varied or with the adoption of dry, or green sand molding methods. Silicon is the element most easily controlled and it is due to its control that semi-steel shell manufacture has been successful in this country.

To arrive at the minimum amount of silicon acceptable, a test is made under the usual working conditions of the plant and the shells that are slightly hardened at the point are analyzed. These will contain the lowest admissible silicon percentage

\section{RULE FOR FIXING SILICON CONTENT}

Experience has shown that to obtain a sufficiently strong metal, the empirical rule

$$
\text { T. C. }+\mathrm{Si}=4.50
$$

must be satisfied. This is the maximum amount of silicon. For instance, if total carbon is 2.80 per cent then $\mathrm{Si}=4.50-2.80=1.70$ per cent. If total carbon is 3.10 per cent then $\mathrm{Si}=4.50-3.10=1.40$ per cent.

The amount of silicon must be kept between the limits of 1.40 and 1.70 per cent, the one corresponding to the minimum of silicon giving the maximum resistance permitted without having chilled castings or shells that are too hard and the other corresponding to the maximum of silicon, above which the castings would be too weak. Care must be exercised to have these figures refer to the final product and, therefore, provision must be made for silicon losses in the cupola.

In working between these limits, analyses made of the actual castings will show that the percentage of combined carbon will be more than 20 per cent of the total carbon necessary to give a satisfactory shell metal. If this figure is not attained, the physical test will not be satisfactory and the shells, when tested will be shattered into small splinters, similar to dust, whereas when 20 per cent or more of combined carbon is obtained, the splinters will be larger and will be more like those of forged steel shells.

Regarding the other elements, phosphorus and sulphur must be kept as low as possible, but it may be stated that satisfactory shells can be made with as much as 0.15 per cent phosphorus and 0.12 to 0.15 per cent sulphur. Phosphorus reduces the strength, but increase the fluidity. Sulphur is without much effect on the strength, but it reduces the fluidity and retains carbon in the combined form. Its action is counterbalanced by the manganese. Sulphur, however, has a tendency to produce blowholes when the metal is not poured at high temperatures and when the mold is not gated to prevent the entrance of air into the mold with the iron.

The CHemical composition and physical tests

Maximum resistance to shock must not be sought, or the tensile strength will not be satisfactory. It must be remembered that a sample giving a high shock resistance will fail in the tensile test, and vice versa. A test bar, breaking under a high falling weight, undoubtedly reveals sluggish iron liable to produce blowholes and to chill at thin points. The tensile test probably will not be satisfactory. Under these circumstances, 
reasonable limits must be fixed in both directions and the rules outlined will enable this result to be obtained.

If a high figure for the falling test and a low tensile test are obtained, silicon must be added.

If the tensile test is high and the falling test too low, carbon must be reduced.

Steel and ferrosilicon, or high silicon iron, are the two agents that will best serve the metallurgist, care being exercised to take into account possible variations in the initial metals used.

\section{FREQUENT ANALYSES AND RAPID TESTS}

It is helpful, of course, to analyze the initial and final products. Though it is difficult to rely entirely upon the regularity of the materials received, it must be admitted that analyses, properly made, are important. All materials should be analyzed, especially iron, scrap, coke, limestone, sand, core oil and finished castings. After a short time these analyses will provide a certain amount of fixed data which will enable the metallurgist to handle with a greater degree of certainty the factors that are with a greater degree of certainty the factors that are
liable to change from day to day. For instance, phosphorus, sulphur and manganese will remain about the
liable to change from day to day. For instance, phossame for each brand of iron, sulphur for each brand of coke, and limestone and sand do not vary much if received from one source. Silicon loss and carbon gain in the cupola will not change much if the same practice is followed every day.

Other faciors, on the other hand, are liable to constant changes; these include silicon in pig metal, moisture in the sand, composition of the core oil, etc. Therefore, analyses must be made as frequently as seems nécessary under the circumstances, always keeping in mind that it is a practical impossibility to work only from analyses particularly on account of the irregularity of the materials.

Either Keep's or a chill test should be made constantly to determine roughly if the amount of silicon is right. If not the iron may be pigged and a part of the loss recovered, or the iron can be improved by additions in the ladle, or changes in the subsequent cupola charges. It is the prevailing practice to add powdered ferrosilicon in the ladle when the iron is too hard.

It also may be necessary, when the product is too variable, to pig a certain amount of metal, for instance, to prepare a low carbon metal from hematite iron and a large percentage of steel to use instead of scrap. It this metal is analyzed it makes more certain obtaining a satisfactory final product. Some firms knowingly in crease their amount of foundry scrap of known composition by making the risers much larger than is really necessary. These processes increase the regularity of the sary. These processes increase the regularity of the work, but at a heavy expense in time and money and they
must only be resorted to when all other means have failed.

A useful, rapid test consists of taking a sample of metal every half hour and pouring it against a chill. The sample is plunged into water when set and is broken immediately. An experienced eye can tell quickly the depth of chill that gives the right metal for the needs of the foundry. This depth is not the same for all classes of shells; it must be less for small, or thin projectiles, than shells; it must be less for small, or thin projectiles, than
for heavy ones. I prefer this to another test recommended by the crdnance department, which consists of pouring cones into open sand molds from time to time, and after cooling the points are broken off for the purpose of ascertaining trom the fracture if the metal is right.

$$
\text { OPERATION OF THE CUPOLA }
$$

The operation of the cupola is similar to that for ordinary work. However, the amount of coke used is somewhat more than the usual average, but not so much as might be imagined. It is generally from 12 to 15 per cent of the charges and this is essential on account of the necessity of having metal much hotter than is obtained usually, if sound castings are to be made. It must be borne in mind that a blowhole which would be unimportant in a machinery casting would not be passed in a shell. Also, it must be remembered that a certain amount of carbon is absorbed by the steel charged before it melts Some foundries are using up to 20 per cent coke, but the writer considers this bad practice, as satisfactory results are obtained with a smaller amount. However in spite of the high price of coke, foundries must not be tempted to reduce its consumption to less than that necessary to obtain the best results. Good shells are obtained regularly when the temperature of the iron at the cupola spout is about 1,450 degrees C. and it must never be less than 1,250 degree $C$. when entering the mold. Unfortunately, there are few practical methods of readily measuring the temperature ot a stream of iron.

$$
\text { RULES FOR CHARGING }
$$

In charging the cupola, the rules laid down by Richard Moldenke may be followed. However, it has been found that better results have been obtained by increasing both coke and iron charges by 50 to 100 per cent over what he recommends. That means that coke charges are 6 to 8 inches high and iron charges in proportion. Differen methods are followed for charging limestone and variations in the amounts used also prevail. With the poo grade of coke now furnished in this country, containing from 16 to 18 per cent of ash, some foundries use up to 12 per cent limestone and add it to all charges, including the bed. This means that charging 12 per cent coke, a much limestone as coke is used. Other foundries use two and one-half times as much limestone as ash in the coke. Good results are obtained with 5 to 6 per cent The pig iron should be broken into small pieces, but is still more important to use steel in small rather than large pieces, as the action of cementation which takes place before liquefaction takes some time and would not place before liquefaction takes some time
be completed if the pieces are too large.

\section{Smelter Fumes}

THE attention of a visitor at one of the large coppe or lead ore reduction works is often arrested by the tremendous quantity of molten slag that is continually being discharged from trains of slag cars and which flowing down the sides of the slag dump, suggests lav flowing down the mountain side from a miniature volcano. The tailings from the concentrating mill form an even greater mass of waste material which, accumulating year after year, frequently builds up artificial mounds more than 100 teet high and covering many acres. Great improvements made in metallurgical processes in the las tew years have made it possible to profitably rework this material at several plants.

The huge fume cloud emitted by the main stack of the smelter, although presenting a striking spectacle as it stretches for miles across the country, is not likely to suggest to the visitor the same possibilities of potential value as the enormous accumulations of waste mentioned. It is bard to realize that the weight of the gases leavin the smelter stack is frequently more than ten times a great as that of the slag that the plant produces, and perhaps three or four times as great as that of the tailings discharged from the concentrating plant.

Although the major part of this gas is air from which the oxygen has been partly removed in the various processes through which it has passed, the gas stream of ten contains other material that, it it could be collected in serviceable condition, would be worth a veritable king's ransom. The substances in the gas stream may be divided into two classes, namely, minute suspended particles of solid and liquid matter, the so-called dust and fume, which render the stack discharge visible to the eye, and the truly gaseous material which is by itsel invisible. The suspended matter is composed of minute particles of ore and other substances from the furnace charge, which are mechanically carried out by the rapidly moving gases, and also of material that has been volatilized by the intense heat of the furnaces and subsequently condensed in the form of liquid or solid particles when the gases have somewhat cooled, just as atmospheric moisture in a warm moist wind from the south condenses into fog when striking colder currents from the north.

The suspended material in the gas stream from a copper smelter will contain in general not only copper stances associated with the copper in the ore. The value of these metallic constituents discharged with the gases by a large smelting plant may amount to several thousand dollars per day, and it is only within recent years that methods have been developed by whicb a part it not al of the suspended material can be removed from the gas stream and subjected to special processes for the recovery of the valuable metals.-Year Book of the U.S. Bureau of Mines.

\section{Animal Camouflage}

Dr. P. Chalmers Mitchell, F.R.S., Secretary of the Zoological Society of London, recently delivered the first lecture of his course on "Animal Camouflage."

The lecturer began by observing that in the animal world more brilliant colors and patterns were hidden than were seen. Animals dredged up from the depths of the sea were, in many cases, brilliantly colored and adorned with intricate patterns. Moreover, colors and patterns were even more conspicuous in the interiors of animals than in their exteriors, as a glimpse at a
butchers' shop in pre-war times would show; and in support of the adage that beauty is skin deep, he sugrested that if the chimpanzee and the orang, were flayed, what remained would be as beautiful as a human being similarly treated.

It was, of course, well known that some animals seem to make themselves as conspicuous as possible, $\boldsymbol{e} . \boldsymbol{g}$., the bird of paradise or the cock pheasant. A favorite ex-
planation of this is the "wedding dress" theory, viz., that the bird puts on his gayest clothes when he goes a courting; but Dr. Chalmers Mitchell inclined to the opinion that, as the hen sits on the eggs and looks after the young, it is important that she should remain as inconspicuous as possible, while the cock endeavors to distract attention from her to himself both by his gay garments and his singing. Other animals, again, like rattlesnakes, try to make themselves conspicuous for different reasons. A snake is a delicate creature, and its ribs, and even its back, are easily broken; and when it is not hunting it lies out in the open, where it will be distinctly seen, and advertises its dangerous presence in the hope that it may not be inadvertently molested.

In most cases animals try to conceal themselves, and one important way of doing so is by endeavoring to match their surroundings. The leaf insect, which is considered good to eat by numerous enemies, is a fine example of this. Another instance shown on the screen was the privet hawk moth. The moth, which flies at night, is dusky, but the caterpillar is bright green, and is hard to see on the leaves of its favorite food.

After describing animals which live in snowy regions, and which have either white coats all the year round, like the polar bear, or summer and winter suits, like arctic foxes, hares, and ermine, the lecturer passed on to spotted and striped animals. Few patterns could be more conspicuous than the spotted coat of the jaguar when seen in a museum or a menagerie; but a remarkable photograph brought out the fact that when in its natural surroundings of forest the beast becomes almost invisible. rounarly, even giraffes blend in with their natural surroundings to such an extent that at a little distance it
extremely difficult to detect them.-English Mechanic.

\section{Experiments in Ray Collecting and Filtering for}

A Writer in the English Mechanic relates the following experiments in making inexpensive ray collectors and filters that may be useful to amateur microscopists. He ays:

"Passing by a restaurant last Friday, I looked in the window, and saw some bottles labelled, 'Vino Chianti'not the wine, but the shape and color of the bottles globular bodies, and were of a curious green color. I went into the shop and asked for an empty one, and was fortunate enough to obtain one for 'tuppence.' When I got home I removed the plaited straw case and filled it with tap water. My idea was that its curious green color would make it a good light filter, and its globular shape a good ray collector. Nor was I disappointed. I lit the gas-lamp, placed the bottle in a glass receptacle to keep it upright, adjusted the burner so that it shone directly through the center of the globular body, and focussed it on to the mirror as if it were an ordinary bull's-eye condenser. The result was most pleasing and effective-almost startling. I tried several objectives, This is only, in ordinary times, a $£ 5$ lens, but it actually does all done by a $\frac{1}{16}$-inch alien fluorite I once used. The proof of its excellence may be guessed when I say The proof of its excellence may be guessed when I say
that with a full solid cone, helped by the aid of my bottlegreen light, it very neatly lined A. pellucida; and when I put in an eighth moon stop it showed what we must, I think, regard its moniliform structure. Did anyone ever before in microscopical experiments employ a winebottle to aid them? I could mention a lot of things I did, but this one must suffice. So encouraged, I thought I would go one better. At the local office of our gas company I was able to get for a shilling an almost perfect globe with only one aperture, and made of better glass than the bottle was, and perfectly transparent. With rain water I made a saturated solution of copper acetate, I adjusted it, and as it was 6 inches in diameter, I cut circular hole 2 inches in diameter, and used that as a diaphragm to the globe. Then I looked at a beautiful group of diatoms with a P. and L. 2/3-inch achromatic. This time I called up all hands to come and look, and one remark made was, "Is it not a pretty sunlit field?" and so it was. Again I could say a lot, but I thought I would go another one better. This time I borrowed a small flask, such as analytical chemists use, made of excellent glass, with a perfectly globular body, and able to stand upright without any aid. This I filled with a mixture of ammonia, sulphate of copper, and distilled water, so arranging matters that the color of the mixture was neither too faint nor too dense. This is now being used on my afternoon collection of alge. It is the most from defects. My next "stunt" is to get a transparent globe used for midget gaslamps, seal up the wider opening, and fill it with 160 grains of copper nitrate, 14 grains of chromic acid, and about 8 ounces of distilled water and shall expect to receive equally good results if I can get a globe free from defects. These collecting lenses and light filters combined take little trouble to accurately adjust, but I wish some readers would try them and record their opinions of their capabilities. 